\title{
Replenishment Policy for Items Having a Fixed Shelf Life under Permissible Delay and Variable Lead Time
}

\author{
Sarbjit Singh \\ Faculty of Operations Management \& Quantitative Techniques, Institute of Management Technology, India
}

Copyright $(\mathcal{C} 2015$ by authors, all rights reserved. Authors agree that this article remains permanently open access under the terms of the Creative Commons Attribution License 4.0 International License

\begin{abstract}
All organizations whether manufacturing or service have to keep inventory for smooth running of their business processes. This study is devoted to the items like medicines, cosmetics which are having a fixed shelf life, i.e. they will be of no use after some prescribed time. This model also considers the permissible delay which means that the buyer can pay for goods after some fixed time and has to pay interest after that fixed time. The demand considered here is fixed constant demand. The lead time varies as per the availability of the product and follows normal distribution.
\end{abstract}

Keywords Inventory Model, Fixed Shelf Life, Cycle Period, Variable Lead Time

\section{Introduction}

One of the most developed fields of operations management is inventory management. Inventory has been defined as idle resources that possess economic value by Monks [1]. To meet demand on time, companies often keep on hand stock that is awaiting sale. The purpose of inventory management is minimizing the cost associated with maintaining inventory and meeting customer demand. The two basic questions of inventory management are (1) when should an order be placed for a product? (2) How large should each order be?

The economic order quantity model was first developed by Ford Harris [2 \&3] but R. H. Wilson [4] applied it extensively that is why this is also known as Harris and Wilson model. There is mention of economic order quantity as minimal quantity, cost in book purchasing and storing by Ralph Currier Davis [5].The objective is to determine economic order quantity, Q, which minimizes the total cost of an inventory system when the demand occurs at a constant rate. Hadley and Whitin [6] has analyzed economic order quantity model and studied its applications in practical problems David Piasecki [7]studied how to optimize cost using EOQ and also deals with the conflict between JIT and EOQ.
Goyal was the first to introduce the concept of permissible delay. Sarkar, Jamal and Wang [8] developed a supply chain model for perishable products under inflation and permissible delay in payment. J.T. Teng [9] who considered the EOQ under condition of permissible delay in payment which is further extended by Ken Chung Kun and Yun-Fu-Huang [10] for limited storage capacity

This paper is an extension of the classical EOQ model in which items considered are perishable items which obsolete after some fixed time. This model converts into a classical EOQ model if shelf life of the items is more than the cycle period; the concept of permissible delay has been included in both classical EOQ as well as the proposed model. Special case has been discussed where this model has been applied and also lead time considered in the model is a probabilistic model which follows normal distribution.

\section{Notation and Assumptions}

The following notations and assumptions are used throughout this paper

$\mathrm{D}_{\mathrm{T}}$ amount of material become during a cycle time, $\mathrm{T}$

$\theta$ deterioration rate, a fraction of the on-hand inventory

c the unit cost per item (dollars/unit)

$\mathrm{s} \quad$ unit selling price $(\mathrm{s}>\mathrm{c})$

A the ordering cost of inventory (dollars/order)

D the demand rate (units per unit time)

$\mathrm{T} \quad$ cycle time

$C_{H} \quad$ the total cost of holding inventory per cycle

$C_{D} \quad$ total obsolete cost per cycle

M the retailer's trade credit period offered by supplier in years

$I_{e} \quad$ interest which can be earned per $\$$ per year

$I_{p} \quad$ interest charges per $\$$ in stocks per year by the supplier

Q the retailer's order quantity per cycle 


\section{Assumptions}

1) The items considered in this model are having a fixed shelf life

2) Shortages are allowed and fully backlogged.

3) The demand is constant

4) $\mathrm{N}$ cycles have been considered in a year

5) Effect of inflation and time value of money both are considered

6) The lead time is probabilistic and follows normal distribution.

7) The lead time is variable.

\section{Mathematical Model and Analysis}

Considering the above assumptions with constant demand, the inventory system goes like this: Initially depletion of the inventory occurs due to demand (supply) only i.e., during the period $\left[0, t_{1}\right]$. For this period the inventory at any time $t$ is given by

$$
\frac{d I(t)}{d t}=-(\alpha+\beta I(t)), 0 \leq t \leq t_{1},
$$

$t_{1}$ is the fixed life of items, after the fixed time items become obsolete

Solving equation (1) and taking into consideration condition that at $\mathrm{t}=\mathrm{T}, \mathrm{I}(\mathrm{t})=0$. Putting this value in the above equation, we get

$$
I(t)=\frac{\alpha}{\beta}\left(e^{\beta[(T-t)]}-1\right), 0 \leq t \leq t_{1},
$$

The order quantity $\mathrm{Q}$, ordered at time $\mathrm{t}=0$ is

$$
Q=\frac{\alpha}{\beta}\left(e^{\beta T}-1\right)
$$

The total variable cost will consist of the following

a) The ordering cost of the materials is fixed at $A$ dollar/order

b) There are two cases for holding or carrying cost, either $\mathrm{t}_{1}<\mathrm{T}$, or $\mathrm{t}_{1} \geq \mathrm{T}$

\section{Case I $-\mathrm{t}_{1}<\mathrm{T}$,}

The holding cost is the function of average inventory cost and it is given by

$$
C_{H}=i c\left[\int_{0}^{t_{1}} I(t) d t\right]
$$

Which, upon simplification, yields

$$
=\frac{i c \alpha}{\beta}\left(\frac{e^{\beta T}-e^{\beta\left(T-t_{1}\right)}}{\beta}-t_{1}\right)
$$

Case II $-\mathrm{t}_{1} \geq \mathrm{T}$
The holding cost is the function of average inventory cost and it is given by

$$
C_{H}=i c\left[\int_{0}^{T} I(t) d t\right]
$$

Which, upon simplification, yields

$$
=\frac{i c \alpha}{\beta}\left(\frac{e^{\beta T}-1}{\beta}-T\right)
$$

c) Obsolescence cost

It occurs only in the case when $\mathrm{t}_{1}<\mathrm{T}$

$$
\begin{gathered}
C_{o}=c\left(Q-(I(T)) t=t_{1}\right) \\
=\frac{c \alpha}{\beta}\left(e^{\beta T}-e^{\beta\left(T-t_{1}\right)}\right)
\end{gathered}
$$

d) According to assumption, there are four cases

Case I $\mathrm{M}<\mathrm{t}_{1}<\mathrm{T}$ or $\mathrm{t}_{1}<\mathrm{M}<\mathrm{T}$ The permissible delay is less than the shelf life and shelf life is less than the cycle period or shelf life is less than permissible delay and permissible delay is less than cycle period

The interest payable $\left(I_{p}\right)$ per cycle

$$
\begin{gathered}
=i_{p} \int_{M}^{T} c Q d t \\
=\frac{\alpha i_{p} c}{\beta}(T-M)\left(e^{\beta T}-1\right)
\end{gathered}
$$

The interest earned $\left(I_{e}\right)$ per cycle is

$$
\begin{gathered}
=s i_{e} \int_{0}^{t_{1}} t(\alpha+\beta I(t)) d t \\
=\frac{s i_{e} \alpha}{\beta}\left(1-e^{\beta\left(T-t_{1}\right)}\right)
\end{gathered}
$$

Total variable cost function per cycle is given by

$$
T V C=A+C_{H}+C_{o}-I_{e}+I_{p}
$$

The Total Variable Cost per unit time, TC, is simply given by

$$
T C=\frac{T V C}{T}
$$

Case II. $\mathrm{M}<\mathrm{T}<\mathrm{t}_{1}$ i.e. the permissible delay time is less than the cycle time and cycle time is less than the shelf life

The interest payable $\left(I_{p}\right)$ per cycle

$$
=i_{p} \int_{M}^{T} c Q d t
$$




$$
=\frac{\alpha i_{p} c}{\beta}(T-M)\left(e^{\beta T}-1\right)
$$

The interest earned $\left(I_{e}\right)$ per cycle

$$
=s i_{e} \int_{0}^{T} t(\alpha+\beta I(t)) d t
$$

Total variable cost function per cycle is given by

$$
T V C=S+C_{D}+C_{H}+I_{p}-I_{e}
$$

Using values obtained in equation (9) and (10), the total variable cost comes out to be

$$
\begin{aligned}
& T V C\left(T, t_{1}\right)=S+c\left[\frac{D}{\vartheta}\left(e^{\vartheta\left(T-t_{1}\right)}-1\right)+D t_{1}-D T\right]+ \\
& +\frac{i c D}{\vartheta^{2}}\left[\frac{\vartheta^{2} t_{1}^{2}}{2}+\left(1+\vartheta t_{1}\right)\left(e^{\vartheta\left(T-t_{1}\right)}-1\right)-\vartheta\left(T-t_{1}\right)\right]+ \\
& +\frac{c i_{p} D}{\theta^{2}}\left(e^{\theta(T-M)}-1-\theta T-\theta M\right)+s i_{e} \frac{D T^{2}}{2}
\end{aligned}
$$
by

The Total Variable Cost per unit time, TC, is simply given

$$
\begin{aligned}
& T C\left(T, t_{1}\right)=\frac{S}{T}+\frac{c}{T}\left[\frac{D}{\vartheta}\left(e^{\vartheta\left(T-t_{1}\right)}-1\right)+D t_{1}-D T\right]+ \\
& +\frac{i c D}{\vartheta^{2} T}\left[\frac{\vartheta^{2} t_{1}^{2}}{2}+\left(1+\vartheta t_{1}\right)\left(e^{\vartheta\left(T-t_{1}\right)}-1\right)-\vartheta\left(T-t_{1}\right)\right]+ \\
& +\frac{c i_{p} D}{\theta^{2} T}\left(e^{\theta(T-M)}-1-\theta T-\theta M\right)-s i_{e} \frac{D T}{2}
\end{aligned}
$$

3) $\mathrm{T}<\mathrm{M}$, In this case no interest is paid but interest is earned. The interest earned $\left(I_{e}\right)$ per cycle is

$$
\begin{gathered}
=\int_{0}^{T} s i_{e} D t d t+\int_{T}^{M} s i_{e} D T d t \\
=s i_{e} \frac{D T^{2}}{2}+s i_{e} D T(M-T)
\end{gathered}
$$

Total variable cost function for one cycle is given by

$$
T V C=S+C_{D}+C_{H}-I_{e}
$$

Using values obtained in equation (9) and (10), the total variable cost comes out to be

$$
\begin{aligned}
& \operatorname{TVC}\left(T, t_{1}\right)=S+c\left[\frac{D}{\vartheta}\left(e^{\vartheta\left(T-t_{1}\right)}-1\right)+D t_{1}-D T\right]+ \\
& +\frac{i c D}{\vartheta^{2}}\left[\frac{\vartheta^{2} t_{1}^{2}}{2}+\left(1+\vartheta t_{1}\right)\left(e^{\vartheta\left(T-t_{1}\right)}-1\right)-\vartheta\left(T-t_{1}\right)\right]- \\
& -s i_{e} \frac{D T^{2}}{2}-s i_{e} D T(M-T)
\end{aligned}
$$

The Total Variable Cost per unit time, TC, is simply given by

$$
\begin{aligned}
& T C\left(T, t_{1}\right)=\frac{S}{T}+\frac{c}{T}\left[\frac{D}{\vartheta}\left(e^{\vartheta\left(T-t_{1}\right)}-1\right)+D t_{1}-D T\right]+ \\
& +\frac{i c D}{\vartheta^{2} T}\left[\frac{\vartheta^{2} t_{1}^{2}}{2}+\left(1+\vartheta t_{1}\right)\left(e^{\vartheta\left(T-t_{1}\right)}-1\right)-\vartheta\left(T-t_{1}\right)\right]- \\
& -s i_{e} \frac{D T}{2}-s i_{e} D(M-T)
\end{aligned}
$$

Using the principle of maxima and minima the appropriate value of cycle time, $T$ can be obtained to minimize the total cost.

\section{Numerical Illustrations}

If we consider four cycles in a year, i.e. $\mathrm{T}=.25$ than optimal order quantity for $\alpha=1000, \beta=.5$ is 267 items.

In case the fixed shelf life is two and a half month, then the number obsolete items is 94 and consider per item cost $\$ 10$ will give the obsolenscence cost as $\$ 940$.

\section{Concluding Remarks}

In this paper the products having stock dependent demand with fixed shelf life has been considered. In most of the previous studies, it has been considered that deterioration of items starts immediately after procurement, which is inaccurate in the majority of the cases. To remove this limitation, in this study, the proposed model considers the items which does not deteriorate but become obsolete after some fixed time.

The theorems prove the validity of the model, as they show both the total variable cost and the average cost are convex. The proposed model can be extended in several ways. For instance, we may consider various demand patterns like an exponential, linear etc, and also can include allowing shortages, time value of money, trade credit and inflation; all these are worthy of future research.

\section{REFERENCES}

[1] Monks, J.G., 1987. Operations Management. 3rd Edn., McGraw-Hill Book Co., New York, pp: 236-334.

[2] Harris, F.W. (1913).How many parts to make at once factory. The Magazine of Management, 10 (2), 135-136.

[3] Harris, F.W. (1915). Operations Cost (Factory Management Series), Chicago: Shaw.

[4] Wilson, R. H. "A Scientific Routine for Stock Control", Harvard Business Review, 13, 116-128 (1934)

[5] Davis, R.C. (1931). Purchasing and Storing, Alexander Hamilton Institute, New York. 
[6] Hadley, G. and T.M. Whitin, Analysis of Inventory Systems, Prentice-hall, Englewood Cliffs, N.J., 1963.

[7] David Piasecki (2009). Inventory Management Explained, www.inventorybook.com

[8] Sarkar, B.R, Jamal A.M.M and Wang, S., 2000. Supply chain model for perishable products under inflation and permissible delay in payment. Computers \& Operations Research, 27, $59-75$.
[9] Teng J. T., (2002). On the economic order quantity under conditions of permissible delay in payments. Journal of the Operational Research Society, 915-918.

[10] Chung K.J. \& Huang Y.F. (2004). Optimal replenishment policies for EOQ inventory model with limited storage capacity under permissible delay in payment Journal of Operational Research Society. 14, 17-22. 